\title{
Biomedical Simulation: Evolution, Concepts, Challenges and Future Trends
}

\author{
Simulação Biomédica: Evolução, Conceitos, Desafios e \\ Estratégias Futuras
}

\author{
Carla SÁ-COUTO $\rrbracket^{1,2}$, Luís PATRÃO ${ }^{3,4}$, Francisco MAIO-MATOS ${ }^{5,6}$, José Miguel PÊGO \\ Acta Med Port 2016 Dec;29(12):860-868 - http://dx.doi.org/10.20344/amp.8403
}

\section{ABSTRACT}

Biomedical simulation is an effective educational complement for healthcare training, both at undergraduate and postgraduate level. It enables knowledge, skills and attitudes to be acquired in a safe, educationally orientated and efficient manner. In this context, simulation provides skills and experience that facilitate the transfer of cognitive, psychomotor and proper communication competences, thus changing behavior and attitudes, and ultimately improving patient safety. Beyond the impact on individual and team performance, simulation provides an opportunity to study organizational failures and improve system performance. Over the last decades, simulation in healthcare had a slow but steady growth, with a visible maturation in the last ten years. The simulation community must continue to provide the core leadership in developing standards. There is a need for strategies and policy development to ensure its coordinated and cost-effective implementation, applied to patient safety. This paper reviews the evolutionary movements of biomedical simulation, including a review of the Portuguese initiatives and nationwide programs. For leveling knowledge and standardize terminology, basic but essential concepts in clinical simulation, together with some considerations on assessment, validation and reliability are presented. The final sections discuss the current challenges and future initiatives and strategies, crucial for the integration of simulation programs in the greater movement toward patient safety.

Keywords: Clinical Competence; Computer Simulation; Education, Medical/methods; Patient Safety; Patient Simulation; Portugal; Simulation Training.

\section{RESUMO}

A simulação biomédica é uma ferramenta educativa para a formação nas ciências da saúde, com aplicação nos vários níveis de ensino. Proporciona experiências ativas e sistemáticas de aprendizagem com o treino de conhecimentos, habilidades e atitudes, de forma segura, pedagogicamente orientada e eficiente. Neste contexto, a simulação biomédica proporciona habilidades e experiência que facilitam a transferência de competências cognitivas, psicomotoras e de comunicação, mudando assim o comportamento e atitudes, aumentando, em última instância, a segurança do doente. Para além do impacto sobre o desempenho individual e de equipa, a simulação proporciona o ambiente ideal para o estudo de falhas organizacionais e teste de melhorias nos desempenhos dos sistemas. Nas últimas décadas, a simulação na área da saúde cresceu lentamente, mas de forma constante, com um amadurecimento significativo nos últimos 10 anos. A comunidade de simulação deve continuar a liderar o estabelecimento de standards nesta área, assim como o desenvolvimento de estratégicas e políticas para assegurar a sua implementação coordenada e custo-efetiva, no aumento da segurança do doente. Este artigo apresenta os movimentos evolutivos da simulação biomédica, incluindo uma revisão das iniciativas portuguesas e programas nacionais. Para nivelar o conhecimento e padronizar a terminologia, são apresentados conceitos básicos, mas essenciais, da simulação clínica, juntamente com algumas considerações sobre avaliação, validação e fiabilidade. As seções finais discutem os desafios atuais e as iniciativas e estratégias futuras, cruciais para a integração de programas de simulação no movimento global de promoção da segurança do paciente.

Palavras-chave: Competência Clínica; Educação Médica/métodos; Portugal; Segurança do Doente; Simulação por Computador; Simulação de Doente; Treino por Simulação.

"Medical error-the third leading cause of death in the US" is the title of a recent published paper, ${ }^{1}$ where an estimative of 251000 deaths/year (in USA) are attributed to errors in patient care. Previous reports from the Institute of Medicine, ${ }^{2,3}$ the National Healthcare System, ${ }^{4}$ and other publications ${ }^{5-6}$ attribute $70 \%-80 \%$ of these errors to poor soft skills, namely communication, leadership, team work, among others. These reports have clear recommendations on the use of simulation to promote patient safety:
- $\quad$ "Another example of ways to prevent and to mitigate harm is simulation training. Simulation is a training and feedback method in which learners practice tasks and processes in lifelike circumstances using models or virtual reality, with feedback from observers, other team members, and video cameras to assist improvement of skills."2;

- "The educational tools should include multimedia, small-group facilitated discussion, problem-based

1. Biomedical Simulation Center. Faculty of Medicine. University of Porto. Porto. Portugal.

2. Center for Health Technology and Services Research (CINTESIS). Faculty of Medicine. University of Porto. Porto. Portugal.

3. Faculty of Health Sciences. University of Beira Interior. Covilhã. Portugal.

4. Internal Medicine Department. Centro Hospitalar Tondela-Viseu. Viseu. Portugal.

5. Department of Ambulatory Surgery and Department of Anesthesia. Coimbra Hospital and Universitary Centre. Coimbra. Portugal.

6. CICS-UBI, Health Sciences Research Center. University of Beira Interior. Covilhã. Portugal.

7. Life and Health Sciences Research Institute (ICVS). School of Medicine. University of Minho. Braga. Portugal.

8. ICVS/3Bs - PT Government Associate Laboratory. Braga/Guimarães. Portugal.

$\bowtie$ Autor correspondente: Carla Sá Couto. csacouto@med.up.pt

Recebido: 31 de outubro de 2016 - Aceite: 05 de dezembro de 2016 | Copyright @ Ordem dos Médicos 2016 
learning and simulation-based exercises. Only through innovative methods that encompass active learning, role modelling and feedback can changes in patient safety be fully realized." 4

Simulation can be defined as a technique to replace or amplify real experiences with guided experiences that evoke or replicate substantial aspects of the real world in a fully interactive manner. ${ }^{7}$ Simulation provides a safe, supportive educational environment, ${ }^{8}$ encouraging acquisition of skills through experience, and stimulating reflection on performance. ${ }^{9}$ As opposed to the clinical setting, where errors must be prevented or repaired immediately to protect the patient, in a simulated environment errors may be allowed to progress, to demonstrate their implications, or to enable a quick reaction to rectify them. ${ }^{10}$

Simulation is a learner-centered educational experience rather than a patient-centered activity. Trainees are exposed to a range of carefully designed clinical encounters, providing the opportunity for the educator to adapt the content, level of difficulty, and sequence in the curriculum, ${ }^{10}$ in order to diagnose and bridge needs to best practices.

In this context, simulation provides skills and experience that facilitate the transfer of cognitive, psychomotor and proper communication competences, thus changing behavior and attitudes, ${ }^{11}$ and ultimately improving patient safety. ${ }^{12}$ Moreover, beyond the impact on individual and team performance, simulation provides an opportunity to study organizational failures and improve system performance. ${ }^{12-14}$

This paper reviews the evolutionary movements of biomedical simulation, including a review of the Portuguese initiatives and nationwide programs. For leveling knowledge and standardize terminology, basic but essential concepts in clinical simulation, together with some considerations on assessment, validation and reliability are presented. The final sections discuss the current challenges and future initiatives and strategies, crucial for the integration of simulation programs in the greater movement toward patient safety.

\section{Biomedical simulation through times}

Simulation, in its many forms, is widespread in several fields of human venture, counting many centuries of history. ${ }^{15}$ In aviation, the first flight simulator appeared in 1928 through the work of Edwin Link. ${ }^{16}$ The modern aviation industry has put a tremendous effort in the development of high-fidelity flight simulation and contributed to the improvement of teams training through crew resource management programs. ${ }^{9}$

In healthcare, primitive forms of simulation have been in use since the $16^{\text {th }}$ century. ${ }^{11}$ The earliest known simulators are obstetric manikins, introduced towards 1700 by Grégoire (Paris), for the practical instruction of midwives. ${ }^{17}$ Physical models of anatomy and disease were constructed long before the advent of modern plastic or computers. ${ }^{15}$

The development of medical part-task trainers arose in late XIX century, although major proliferation was during the 1940s, with the development of plastic and synthetic materials. ${ }^{19}$

It was only in the 60 s, that significant development originated a steady movement towards clinical simulation. In 1960, Äsmund Laerdal, a Norwegian toy manufacturer, developed the first trainer in the history of medical simulation. Resusci ${ }^{\circledR}$ Annie was initially designed for the practice of mouth-to-mouth breathing but rapidly an improved version was released for the training of cardiopulmonary resuscitation, ${ }^{15}$ revolutionizing resuscitation training.

Other more sophisticated part-task trainers, such as Harvey (cardiology patient simulator) developed by Michael Gordon of the University of Miami Medical School, were developed in the late 60s. ${ }^{9,18}$ Harvey played an important role on the development of more complex part-task trainers as it was the first to combined static models with audiovisual and interactive cues. Part of its innovation was the integrated curriculum of cardiovascular conditions, with associated learning goals. ${ }^{18}$

The use of standardized patients in medical education is thought to have begun in 1963. ${ }^{10,19}$ This consists in (formal or informal) actors trained to role-play patients, for training and assessment of history taking, physical examination, and communication skills.

The first primitive full-body human patient simulator, Sim-One, was built by Stephen Abrahamson and Judson Denson at the University of Southern California in 1966, and was used for anesthesia training. ${ }^{20}$ Two decades later, with the advances in computer technology and bioengineering, other high-fidelity simulators began to be developed, as a result of academic efforts. ${ }^{21,22}$ Some of these went on to be commercial products, a few still currently available. One example is the CASE (Comprehensive Anesthesia Simulation Environment), developed by David Gaba at Stanford University which was commercially available for a number of years. ${ }^{9,23}$ Another example is the Gainesville Anesthesia Simulator, developed by a group of researchers led by Michael Good and Joachim Gravenstein at the University of Florida, the precursor of many products currently commercialized by CAE Healthcare.9,23 These simulators, and others developed in Europe, formed the grounds for the modern simulators currently available.

In the 90s, Delp and Colleagues developed the first surgical simulator to teach lower limb reconstruction surgery and, by the late $90 \mathrm{~s}$, basic virtual reality models were being commercialized. ${ }^{24}$ Concerns on their efficacy put them on hold until 2002, when a double blinded study proved that trainees could reduce significantly their procedure times and that injury was reduced to a fifth, after using a virtual reality trainer. ${ }^{24}$

Prompted by technological innovation and reforms in healthcare education, ${ }^{9}$ a more receptive atmosphere for the use of simulators started to emerge in the 1990s. Pressures arising from the limited receptivity of patients to be involved in training, limited instruction time, increasingly complex technical procedures, and ethical issues raised by the patient safety movement also contributed to these 
changes. ${ }^{17,25}$

In response to the expanding interest in this field, two societies were established: the Society in Europe for Simulation Applied to Medicine (SESAM - www.sesam-web. org) founded in August 1994, and the Society for Simulation in Healthcare (SSH - www.ssih.org), established in January 2004. Scientific publications entirely devoted to healthcare simulation emerged from these societies. Simulation in Healthcare (the official journal of the $\mathrm{SSH}$ ) was launched in January 2006 and Advances in Simulation (the official journal of SESAM) released its first issue in January 2016.

These concomitant, yet asynchronous, movements were central to the understanding and development of simulation-based education, training and assessment. The anesthesiology community played an important role in the development of sophisticated full-body patient simulators, ${ }^{20-23}$ and in the establishment of frameworks for the integrated training of technical and non-technical skills. ${ }^{26-28}$ The development of simulation programs driven by learning needs (rather than simulation technology), including concepts of crisis resource management (nontechnical skills required for effective teamwork in a crisis situation), led to significant advances in clinical team-based training. ${ }^{29}$

\section{Biomedical simulation in Portugal}

Simulation, in some basic forms, is present in Portuguese healthcare training since the 70s, mainly through the use of anatomic models and part-task trainers. In 1998, biomedical simulation was formally recognized as a research area, at the Institute for Biomedical Engineering (INEB), with the creation of the Modeling and Simulation Group. Several research projects were developed in close collaboration with international simulation companies, being some currently on the market.

The first record of a formal structured simulation center in Portugal dates to $2003 .{ }^{30}$ Since then, other simulation centers were created or emerged from previous initiatives, both in public medical and nursing schools, as in public hospitals. Some private simulation centers have also been developed or have planned to start their activities in near future, although their scope is not made available yet.

Up to our knowledge (personal communications), there are around thirteen formally constituted simulations centers in Portugal, Table 1 (non-exhaustive list). Most of them started as in-house teaching facilities, dedicated to undergraduate or postgraduate training. A number of those evolved to national course providers reaching students and/ or healthcare professionals throughout the country.

There has been a growing concern in faculty development, leading to formal instructor training in simulation and debriefing techniques in internationally recognized centers. Some instructors/centers have established collaborations and participate in faculty training abroad. In Europe, one of the most relevant in this area is the EuSim Group (www. eusim.org) which has a national representative and has performed several courses in Portugal in the past years.

Formal integration of simulation in healthcare sciences education has increased in the last years, benefiting of the current curricular reforms. Most national pre-graduated healthcare curricula have included simulation as an educational strategy to complement traditional methods. Some schools have also developed simulation-based postgraduate courses or residency training. One example is the hands-on obstetric courses, sponsored by the Colégio da Especialidade de Ginecologia/Obstetrícia da Ordem dos Médicos since 2009, available in several simulation centers throughout the country. Several simulation centers also offer carefully structured courses for anesthesiology residency training, and recently the Colégio da Especialidade de Anestesiologia da Ordem dos Médicos recommended the use of simulation in residency training. ${ }^{31}$

Research in biomedical simulation methodologies and tools continues to grow. Several national simulation centers have regular scientific production on the forms of MSc and $\mathrm{PhD}$ thesis, scientific indexed publications, technology

Table 1 - Portuguese simulation centers (non-exhaustive list). Sorted by geographic location.

\begin{tabular}{|c|c|}
\hline Official name & Institution \\
\hline Laboratório de Aptidões Clínicas & Escola de Medicina da Universidade do Minho \\
\hline Centro de Simulação Biomédica da FMUP & Faculdade de Medicina da Universidade do Porto \\
\hline Centro Biomédico de Simulação CHP/ICBAS & Centro Hospitalar do Porto / Instituto de Ciências Biomédicas Abel Salazar \\
\hline Centro de Simulação Médica do Porto & Private \\
\hline Centro de Simulação Clínica da Universidade de Aveiro & Escola Superior de Saúde da Universidade de Aveiro \\
\hline Laboratório de Competências & Faculdade de Ciências da Saúde da Universidade da Beira Interior \\
\hline Centro de Simulação Biomédica de Coimbra & Centro Hospitalar e Universitário de Coimbra \\
\hline Centro de Simulação de Práticas Clínicas & Escola Superior de Enfermagem de Coimbra \\
\hline Centro de Simulação de Práticas de Enfermagem & Escola Superior de Saúde de Portalegre \\
\hline Centro de Simulação de Técnicas em Pediatria & Hospital de Dona Estefânia \\
\hline Centro de Simulação Biomédica & Unidade de Ensino, Formação e Investigação da Saúde Militar, Forças Armadas Portuguesas \\
\hline Laboratório de Aptidões & Departamento de Ciências Biomédicas e de Medicina, Universidade do Algarve \\
\hline Centro de Simulação Clínica da Madeira & Serviço de Saúde da Região Autónoma da Madeira \\
\hline
\end{tabular}


transfer and participation on national and international scientific meetings.

In 2011, SPSim - Portuguese Society for Simulation in Health Sciences (www.spsim.pt) - emerged as a result of a collaborative project of most Portuguese medical schools and simulation training centers. With a wide range of representative members from most of the medical specialties and related health sciences, SPSim has been responsible for the promotion, dissemination and development of simulation based training, teaching and research in Portugal. Its mission includes:

1. Bring forward biomedical simulation as a training resource that contributes to patient safety, excellence of care and humanization of health care;

2. Contribute to the definition, implementation and monitoring of national strategies to apply simulation to health sciences teaching;

3. Promote national and international sharing, research and experience in biomedical education with simulation. Although a young society, SPSim has the strength of a vigorous national network supported in international affiliations, as SESAM and SSH, and productive partnerships with strategic national societies, such as ABRASSIM (Brazilian Association of Simulation in Health - www.abrassim.com.br) and SESSEP (Spanish Society for Clinical Simulation and Patient Safety - www.sessep.com).

To promote national bounding and exchange of experiences, SPSim organized three national simulation meetings held in Braga (2012), Covilhã (2013) and Porto (2015). These events involved a large number of national and international participants, attracted by an appealing and experiential panel that addressed the major breakthroughs and developments in simulation applied to healthcare, from educational and/or clinical practice to research and technology.

Portugal has also received several major international healthcare simulation conferences: SESAM 2006 (Porto), SESAM-ALASIC 2009 (Coimbra), and SESAM 2016
(Lisbon). The later was organized by SPSim, being the first SESAM event organized by a national simulation society. The great success of SESAM 2016 potentiates and stimulates the expansion of biomedical simulation in Portugal.

Further information on specific programs or simulation centers can be consulted through the websites and contacts provided in Table 1.

\section{Basic concepts of clinical simulation Tools}

There are a number of simulation tools ranging from simple to complex, existing desktop software platforms, part-task trainers, full-body high fidelity simulators and live actors acting as standardized patients (SPs). ${ }^{19}$ Each tool has a role in the simulation based learning cycle, and its correct use and application can potentiate the learning outcome, Table 2. Hybrid simulation, the combination of two or more tools - e.g. part-task trainer with standardized patient, should also be considered to augment the realism and to promote the integrated training of technical and soft skills.

\section{Scenario design}

The scenario should be designed and developed based on the learning objectives and expected learning outcomes. ${ }^{29}$ These objectives must take into account the target audience and the training needs. If the acquisition of a technical skill is the learning goal, the scenario design is minimal and can simply be a part-task trainer placed on a table. On the other hand, if the learning goal is nontechnical skills (or a combination of both), the design must be carefully thought, promoting the training of the specific skill(s) by challenging the participants in a realistic clinical case/environment. The later requires a higher investment in time, resources (human and equipment), and preparation. A scenario script/template is extremely useful to organize and standardize all aspects related with the scenario.

\begin{tabular}{|c|c|c|}
\hline Location (city) & Website & Contact \\
\hline Braga & https://www.med.uminho.pt/pt/Escola/Paginas/Laboratorio-de-Aptidoes-Clinicas.aspx & lac@med.uminho.pt \\
\hline Porto & $\underline{\text { http://simulacao.med.up.pt }}$ & simulacao@med.up.pt \\
\hline Porto & http://www.chporto.pt/pagina.php?id=19 & centro.simulacao@chporto.min-saude.pt \\
\hline Porto & http://www.cesimed.pt/ & geral@cesimed.pt \\
\hline Aveiro & https://www.ua.pt/essua/simula/ & essua-simula@ua.pt \\
\hline Covilhã & http://www.ubi.pt/Entidade/LaC & lac@fcsaude.ubi.pt \\
\hline Coimbra & http://www.simcoimbra.org/ & info@simcoimbra.org \\
\hline Coimbra & https://www.esenfc.pt/pt/page/3487 & esenfc@esenfc.pt \\
\hline Portalegre & http://www.essp.pt/novo/index.php/links-de-interesse/80-artigos/154-simula-enfer & geral@essp.pt \\
\hline Lisboa & $\underline{\text { https://cstpediatria.wordpress.com/ }}$ & pmcgarcia@gmail.com \\
\hline Lisboa & http://www.emgfa.pt/pt/organizacao/dirsam/uefism & Not available \\
\hline Faro & https://dcbm.ualg.pt/pt/content/laboratorios-aptidoes-lab & dcbm@ualg.pt \\
\hline Funchal & https://www.sesaram.pt/cscm/ & pedromcr60@gmail.com \\
\hline
\end{tabular}


Table 2- Biomedical simulation tools

\begin{tabular}{|c|c|c|c|}
\hline Category & Description & Application & Example \\
\hline $\begin{array}{l}\text { Standardized } \\
\text { patients }\end{array}$ & $\begin{array}{l}\text { (Formal or informal) actors } \\
\text { trained to role-play patients } \\
\text { or relatives }\end{array}$ & $\begin{array}{l}\text { For training and assessment } \\
\text { of history taking, physical } \\
\text { examination, and } \\
\text { communication skills }\end{array}$ & \\
\hline $\begin{array}{l}\text { Part-task } \\
\text { trainers }\end{array}$ & $\begin{array}{l}\text { Represent a part of the } \\
\text { body and often consist of a } \\
\text { limb, or other body part or } \\
\text { structure }\end{array}$ & $\begin{array}{l}\text { Intended for the training } \\
\text { of technical, procedural or } \\
\text { psychomotor skills }\end{array}$ & \\
\hline $\begin{array}{l}\text { Complex task } \\
\text { trainers }\end{array}$ & $\begin{array}{l}\text { Combine static models with } \\
\text { audiovisual and interactive } \\
\text { cues. Virtual reality } \\
\text { simulation can be included in } \\
\text { this category. }\end{array}$ & $\begin{array}{l}\text { Training and assessment } \\
\text { of complex procedures or } \\
\text { tasks }\end{array}$ & \\
\hline $\begin{array}{l}\text { Screen-based } \\
\text { (software) }\end{array}$ & $\begin{array}{l}\text { Can be simple self-tutorials } \\
\text { or more sophisticated tool } \\
\text { reacting appropriately to } \\
\text { the trainee actions, and } \\
\text { providing feedback on } \\
\text { decisions and actions }\end{array}$ & $\begin{array}{l}\text { Training and assessment } \\
\text { of clinical knowledge and } \\
\text { decision making }\end{array}$ & \\
\hline Full-body patient & $\begin{array}{l}\text { Consist of a full-body } \\
\text { manikin, a computer } \\
\text { workstation, and interface } \\
\text { devices that activate manikin } \\
\text { signs and drive emulated or } \\
\text { actual monitors }\end{array}$ & $\begin{array}{l}\text { Training of complex and } \\
\text { high-risk clinical situations } \\
\text { in a lifelike team training } \\
\text { setting }\end{array}$ & \\
\hline Hybrid & $\begin{array}{l}\text { Combination of two or more } \\
\text { of the above tools }\end{array}$ & $\begin{array}{l}\text { Augment the realism and/ } \\
\text { or to promote the integrated } \\
\text { training of technical and soft } \\
\text { skills }\end{array}$ & \\
\hline
\end{tabular}

Accordingly to the degree of complexity of the skill being practiced or tested, a certain level of fidelity or realism might be more or less suitable.

\section{Simulation session}

A simulation session typically includes three stages: briefing, scenario and debriefing/ feedback.

1. Briefing. Provides a ground for the simulated 
experience and promotes the engagement of the trainee(s). Briefing the room, equipment, and the simulation process (including debriefing/feedback) is essential for a valuable learning experience;

2. The scenario. Consists in the actual performance of a trainee or trainees in a specific simulated situation. It can range from basic settings for individual technical skills training to immersive environments for team training;

3. Debriefing and feedback. These remain fundamental elements of simulation-based learning. ${ }^{32}$ Feedback is specific information about the comparison between a trainee's observed performance and a standard, and is given with the intent to improve/enhance the trainees' performance (mainly on technical skills). Debriefing is an assembly of participants and facilitator(s) in which a recent event can be recalled, analyzed and reflected upon in order to agree on future practice changes. Typically topics that may benefit from debriefing are team training, crisis resource management skills and multidisciplinary training. ${ }^{33}$ Feedback is mostly what was done and debriefing is mostly why it was done.

\section{Assessment, reliability and validity in clinical simulation Assessment}

Assessment is one of the most significant events in the life of a higher education trainee both at pre- and postgraduate levels. Besides its role in establishing the level of one's competency, assessment is one of the most powerful drivers for learning. Assessment should be part of an integrated approach to teaching/learning process in which assessment may be part of the feedback process, quality assurance or licensing steps. This constructive alignment of the educational process ${ }^{34,35}$ is paramount to ensure that the learning goals projected for each level of training reaches the desired. According to Miller, ${ }^{36}$ the medical graduate development progresses from purely cognitive knowledge level (Knows, Knows how) at the novice stage through increasing levels of operational tasks (Shows how) that characterize the competent trainee until it reaches the practicing expert (Does). While it is possible to assess the first levels with written exams and other cognitive tools it is impossible to use them to test procedural skills. The use of simulation tools provides therefore a mean to test higher levels of competency in a standardized environment while at the same time avoiding any harm to patients.

Assessment can be used with different goals according to the necessity of the student/institution, namely:

1. Identify learning needs;

2. Set professional standards of competence and performance;

3. Rank applicants for recruitment.

In the first situation, also known as formative assessment, simulation tools are used as a means to identify the trainee needs at a specific level of development. This has been the mainstay of several simulation courses and programs that rely on feedback techniques specially designed to imprint permanent changes in behavior that lead to best practices. ${ }^{37}$ Although these assessment tasks are generally considered as low stakes, since they do not have a direct impact on the trainee's curricular progression they can be powerful modulators and have a direct impact on the practice of clinicians and ultimately lead to improved care. ${ }^{38}$

Assessment aiming at goals 2 and 3 is referred as summative assessment and is characterized as of high stakes (e.g. setting minimal competency to pass a final) or high-high stakes (e.g. if is a life determining decision such as a licensing exam). In either case, clinical simulation provides an affordable mean to test procedural tasks with high reproductivity in a realistic environment. Part-tasks trainers are inexpensive allowing the reproduction of several procedural tasks (e.g. IV-line placement) that could not be assessed in real life conditions without comprising patient safety. Standardized patients and full-body high-fidelity simulators are more expensive to acquire and maintain but provide a highly realistic scenario that is useful to test complex tasks such as history taking or teamwork.

\section{Reliability and validity}

Reliability and validity are concepts intimately related to the assessment process. ${ }^{39}$ Reliability refers to the desired consistency (or reproducibility) of test scores. In other words, it is the degree to which individuals' deviation scores remain relatively consistent over repeated application of the same test or alternate test forms. Validation is a process by which a test developer or test user collects evidence to support the types of inferences that are to be drawn from test scores. There are two main categories used to assess the validity of a test: content (appropriateness of content) and criterion (relation to other measures).

Simulation based assessment presents issues concerning both reliability and validity. Despite the fact that one of the advantages of using simulators and standardized patients is the consistent reproducibility of behavior, reliability is typically not very high in these settings when compared to assessment of cognitive skills (e.g. multiple choice items). This phenomenon can be ascribed to a sampling effect since simulation based assessment typically comprises a limited number of stations for any number of reasons (limited number of simulators, time, logistics, etc.), especially if the assessment is based in a small number of long duration simulation sessions. To limit this effect, many institutions have adopted some form of OSCE (objective structured clinical examination) assessment with a significant number of stations (8 to 12), with more objective and time limited scenarios.

The most important aspect to reach adequate reliability is the time spent during the assessment. ${ }^{40}$ Another source of variance that affects reliability is the nature of the scoring system (automatic vs human dependent) and how the scorer interferes with the scenario itself. If the scorer is a third-party present in the room, there is a bias effect of the candidate knowing that there is a direct observer leading to conscious behavior towards pleasing/probing the scorer in 
the room. There are several solutions to overcome these issues namely, using video recordings/streaming in order to isolate the scorer from the scenario, using SP as the scorer, using one-way windows, etc. Additionally, the training effect that is observed in candidates is considerable reducing the possibility to test in different conditions than those that were applied during training, especially when using parttask trainers. This phenomenon is less evident with SPs or scenarios designed to assess soft skills since there is more liberty to variations in scenario.

\section{Current challenges}

Choosing the correct simulation tool for the selected learning objective(s) is a permanent challenge. The continuous development of more sophisticated simulation tools provides a spectrum of possibilities towards clinical simulation. Nevertheless, low-cost approaches can equally provide effective learning and have the potential to be used globally. Inexperienced simulation users are many times tempted to use highly sophisticated equipment inadequately, creating artificial and unrealistic scenarios with unnecessary complexity.

Integrating simulation-based training into healthcare curricula continues to be a challenge. Ideally this integration should be transversally to the different levels of education, to ensure the continuity between simulated and clinical learning environments. If the curricula are artificially adapted to include simulation encounters, it can promote negative learning. ${ }^{41}$ Poorly designed simulation scenarios and inadequate instruction may encourage shortcuts, such as omitting patient consent and safety procedures, or it may promote unnatural rather than genuine communication skills. ${ }^{41}$ Moreover, although simulation is widely used for teamwork training, the full integration of surgical, anesthetic, nursing and other key members of a healthcare team (e.g. operating room team) remains a challenge. ${ }^{42}$

Validity in simulation based assessment is an important issue. While content validity is usually achieved at the level of the construct, face validity is many times challenged by assessors and assesses. These issues are mainly related to the unrealistic nature of some models and mannequins that obstacles to the participant to perceive a scenario as real (e.g. cyanosis is very difficult to represent although it is a relevant alert sign). Criterion validity (the possibility to predict later performance in a related criterion) is difficult to achieve, but when achieved it generates real impact in patient outcomes. ${ }^{38}$ It is questioned if learning to perform a task in a mechanical model leads to adequate changes in behavior or if it reflects a training effect similar to playing a video-game. Despite all these challenges, a well-designed simulation based assessment can achieve high standards and are used in several licensing exams throughout the world. ${ }^{43,44}$

Translational research and evidence-based studies of the impact of simulation on patient safety are sparse. In scientific literature, there are innumerous satisfaction studies or educational impact studies supporting systematic acceptance and widespread use of simulation but only few studies $^{45,46}$ show evidence of simulation-based training in patient outcomes. These studies are demanding and costly but essential to better understand and demonstrate the real impact of simulation on patient safety.

The sustainability of simulation programs is dependent of multiple factors such as: institutional commitment, ${ }^{47}$ strong leadership, ${ }^{47}$ a curriculum relevant to clinical practice, ${ }^{47}$ funding, ${ }^{48}$ adequate equipment, ${ }^{47-49}$ faculty development, stable group of instructors and technicians, among others. Consistent funding for both human and physical resources is essential to address long-term goals of the programs. ${ }^{49}$ An understanding of the cost-effectiveness of simulation will enable educators, institutions and healthcare systems to make informed choices with regard to the use of simulationbased medical education programs. ${ }^{13}$

\section{The future: moving towards excellence}

Over the last decades, simulation in healthcare had a slow but steady growth, with a visible maturation in the last ten years. Simulation-based training has been proved to be an effective educational complement for clinical skills acquisition. ${ }^{46}$ It enables knowledge, skills and attitudes to be acquired in a safe, educationally orientated and efficient manner, facilitating the transfer of cognitive, psychomotor and soft skills to improved patient care and better patient outcomes.

To move towards excellence and overcome the current challenges, a number of initiatives must be implemented and developed ${ }^{7}$ :

1. Integrating different types of simulation across different dimensions of applications, purposes, and target populations;

2. Assessing the impact or benefit of simulation based training across the various dimensions;

3. Developing applications for units of participation larger than clinical teams (e.g. entire health care organizations);

4. Establishing benchmarks and criteria for competency based performance assessment using simulation;

5. Investigating fundamental aspects of human performance in health care using simulation;

6. Use of simulation for usability testing of medical devices and patient care processes, if possible at an early, prototype stage, and before deployment.

The simulation community must continue to provide the core leadership in developing standards. ${ }^{7}$ Some efforts have been made to set a ground for this process: $\mathrm{SSH}$ accreditation of healthcare simulation programs was implemented in 2010; SESAM accreditation of simulation based educational institutions started this year; the Aspire Initiative from the Association for Medical Education in Europe (AMEE) will include in 2017 biomedical simulation in the subjects recognized with excellence in education.

Moreover, simulation community must also take the responsibility of implementing strategies for the use of simulation to improve patient safety. ${ }^{7}$ National and international simulation societies, together with healthcare 
and education stakeholders, must lead these initiatives, promoting integrated and funded training programs for healthcare providers at all stages. Policy development is needed to ensure its coordinated and cost-effective implementation. Instead of an independent educational initiative, it should be integrated in the greater movement toward patient safety. As Gaba7 stated in his vision, in 2004, "the major revolution enabled by simulation can only be achieved if the relevant applications are fully integrated into the routine fabric of health care delivery."

\section{PROTECTION OF HUMANS AND ANIMALS}

The authors declare that the procedures were followed according to the regulations established by the Clinical Research and Ethics Committee and to the Helsinki Declaration of the World Medical Association.

\section{REFERENCES}

1. Makary MA, Daniel M. Medical error-the third leading cause of death in the US. BMJ. 2016;3:353-i2139.

2. Kohn L, Corrigan J, Donaldson M, editors. To err is human: building a safer health system. Committee on Quality in America. Washington: National Academy Press; 1999.

3. Crossing the quality chasm: A new health care system for the $21^{\text {st }}$ century. Washington: National Academy Press; 2001.

4. National Patient Safety Agency. Seven steps to patient safety: full reference guide. London: NHS; 2004.

5. Donaldson MS. An overview of to err is human: re-emphasizing the message of patient safety. In: Hughes RG, editor. Patient safety and quality: an evidence-based handbook for nurses. Rockville: Agency for Healthcare Research and Quality; 2008.

6. Pham JC, Aswani MS, Rosen M, Lee H, Huddle M, Weeks K et al. Reducing medical errors and adverse events. Annu Rev Med. 2012.63:447-63.

7. Gaba DM. The future vision of simulation in health care. Qual Saf Health Care. 2004;13:i2-10.

8. Gordon J, Wilkerson W, Shaffer D, Armstrong E. Practicing medicine without risk: students' and educators' responses to high-fidelity patient simulation. Acad Med. 2001;76:469-72.

9. Bradley P. The history of simulation in medical education and possible future directions. Med Educ. 2006;40:254-62.

10. Ziv A, Small SD, Wolpe PR. Patient safety and simulation-based medical education. Med Teach. 2000;22:489-95.

11. Ziv A, Wolpe PR, Small SD, Glick S. Simulation-based medical education: an ethical imperative. Simul Healthc. 2006;1:252-6.

12. Aggarwal $R$, Mytton OT, Derbrew M, Hananel D, Heydenburg $M$, Issenberg B, et al. Training and simulation for patient safety. Qual Saf Health Care. 2010.19:i34-43.

13. Aggarwal R, Darzi A. Simulation to enhance patient safety: why aren't we there yet? Chest. 2011:140:854-8.

14. Walker ST, Brett SJ, McKay A, Aggarwal R, Vincent C. The "Resus:Station": the use of clinical simulations in a randomised crossover study to evaluate a novel resuscitation trolley. Resuscitation. 2012;83:1374-80.

15. Rosen KR. The history of medical simulation. J Crit Care. 2008;23:15766.

16. The Link Trainer [Web site]. Stark Ravings. [Accessed: 2016 Oct 31] Available at: http://www.starksravings.com/linktrainer/linktrainer.htm.

17. Buck GH. Development of simulators in medical education. Gesnerus. 1991;48:7-28.

18. Cooper JB, Taqueti VR. A brief history of the development of mannequin simulators for clinical education and training. Qual Saf Health Care. 2004;13:i11-8.

19. Okuda Y, Bryson EO, DeMaria S Jr, Jacobson L, Quinones J, Shen B, et al. The utility of simulation in medical education: what is the evidence? Mt Sinai J Med. 2009;76:330-43.

20. Denson JS, Abrahamson S. A computer-controlled patient simulator. JAMA. 1969;208:504-8.

21. Gaba DM, DeAnda A. A comprehensive anesthesia simulation environment: re-creating the operating room for research and training.

\section{DATA CONFIDENTIALITY}

The authors declare having followed the protocols in use at their working center regarding patients' data publication.

\section{CONFLICTS OF INTEREST}

All authors are board members of SPSim and simulation instructors in national or international public and/or private institutions. LP is CEO at UpHill, Lda. JMP is an associate of iCognitus4ALL - IT Solutions. None of these companies or institutions influenced, participated or contributed to the content of this paper.

\section{FUNDING SOURCES}

No subsidies or grants contributed to this work.

Anesthesiology. 1988;69:387-94

22. Gravenstein JS. Training devices and simulators. Anesthesiology. 1988;69:295-7

23. Cumin D, Merry AF. Simulators for use in anaesthesia. Anaesthesia. 2007;62:151-62

24. Bahsoun AL, Wheatstone $S$, Challacombe B. Simulation in historical perspective: the history of medical and surgical simulation. In: Dasgupta P, Ahmed K, Jaye P, Khan MS, editors. Surgical Simulation. London: Anthem Press; 2014

25. Issenberg SB, McGaghie WC, Hart IR, Mayer JW, Felner JM, Petrusa $E R$, et al. Simulation technology for health care professional skills training and assessment. JAMA. 1999;282:861-6.

26. Gaba DM, Howard S, Fish K, Smith B, Sowb Y. Simulation-based training in anesthesia crisis resource management (ACRM): A decade of experience. Simul Gaming. 2001,32:175-93.

27. Fletcher G, Flin R, McGeorge P, Glavin R, Maran N, Patey R. Anaesthetists' non-technicalsSkills (ANTS): evaluation of a behavioural marker system. Br J Anaesth. 2003.90:580-8.

28. Gaba DM. Crisis resource management and teamwork training in anaesthesia. Br J Anaesth. 2010;105:3-6

29. Hellaby M. Healthcare simulation in practice. Keswick: M\&K Publishing; 2013.

30. Faculdade de Medicina da Universidade do Porto. Estatutos - Artigo 30. In Diário da República, II série, $n^{\circ} 243,20$ de outubro de 2003.

31. Programa de Formação da Área de Especialização de Anestesiologia [Web site]. In Diário da República, I série,nº 74, 15 de abril de 2016. [Accessed 2016 Oct 31] Available at: https://www.ordemdosmedicos.pt/ send_file.php?tid=ZmljaGVpcm9z\&did=dcf6070a4ab7f3afbfd2809173e $0824 \bar{b}$

32. Gardner R. Introduction to debriefing. Semin Perinatol. 2013;37:166-74.

33. Fanning R, Gaba D. The role of debriefing in simulation-based learning. Simul Healthc. 2007;2:115-25.

34. Biggs J, Tang C. Teaching for quality learning at university. Maidenhead: McGraw-Hill and Open University Press; 2011.

35. Biggs J. Aligning teaching and assessment to curriculum objectives [online publication]. 2003. Teaching and learning in higher education: new trends and innovations. [Accessed 2016 Oct 31] Available at: http:// ucsc.cmb.ac.lk/wiki/images/2/2c/CA1.pdf

36. Miller GE. The assessment of clinical skills/competence/performance. Acad Med. 1990;65:S63-7.

37. Rudolph JW, Simon R, Dufresne RL, Raemer DB. There's no such thing as "nonjudgmental" debriefing: a theory and method for debriefing with good judgment. Simul Healthc. 2006;1:49-55.

38. Siassakos D, Hasafa Z, Sibanda T, Fox R, Donald F, Winter C, et al. Retrospective cohort study of diagnosis-delivery interval with umbilical cord prolapse: the effect of team training. BJOG. 2009;116:1089-96.

39. Crocker LM, Algina J. Introduction to classical and modern test theory. Madrid: Cengage Learning; 2008.

40. van der Vleuten CP, Schuwirth LW. Assessing professional competence: from methods to programmes. Med Educ. 2005;39:309-17.

41. Weller JM, Nestel D, Marshall SD, Brooks PM, Conn JJ. Simulation in clinical teaching and learning. Med J Aust. 2012;196:594. 
42. Kneebone RL, Nestel D, Vincent C, Darzi A. Complexity, risk and simulation in learning procedural skills. Med Educ. 2007;41:808-14.

43. Gale TC, Roberts MJ, Sice PJ, Langton JA, Patterson FC, Carr AS, et al. Predictive validity of a selection centre testing non-technical skills for recruitment to training in anaesthesia. Br J Anaesth. 2010;105:603-9.

44. Cuddy MM, Winward ML, Johnston MM, Lipner RS, Clauser BE. Evaluating validity evidence for USMLE step 2 clinical skills data gathering and data interpretation scores: does performance predict history-taking and physical examination ratings for first-year internal medicine residents? Acad Med. 2016;91:133-9.

45. Zendejas B, Brydges R, Wang AT, Cook DA. Patient outcomes in simulation-based medical education: a systematic review. J Gen Intern
Med. 2013.28:1078-89

46. McGaghie WC, Issenberg SB, Cohen ER, Barsuk JH, Wayne DB. Does simulation-based medical education with deliberate practice yield better results than traditional clinical education? A meta-analytic comparative review of the evidence. Acad Med. 2011;86:706-11.

47. Ayres-de-Campos D, Deering S, Siassakos D. Sustaining simulation training programmes - experience from maternity care. BJOG. 2011;118: 22-6.

48. Maloney S, Haines T. Issues of cost-benefit and cost-effectiveness for simulation in health professions education. Adv Simul. 2016;1:13.

49. Levine AI, DeMaria S, Schwartz AD, Sim AJ, editors. The comprehensive textbook of healthcare simulation. New York: Springer; 2013. 